\title{
COMPANHEIROS SERVIDORES: o avanço do sindicalismo do setor público na CUT $^{*}$
}

\author{
Sidney Jard da Silva
}

\section{Introdução}

Em agosto de 2000, no VII Congresso Nacional da Central Única dos Trabalhadores (VII CONCUT), o professor João Felício, ex-presidente do Sindicato dos Professores do Ensino Oficial do Estado de São Paulo (APEOESP), foi eleito presidente da CUT.

Tal fato reacende um controverso debate sobre o sindicalismo do setor público na CUT: de um lado, os críticos da Central, referindo-se à expressiva participação dos servidores públicos e empregados em empresas estatais nas instâncias deliberativas da entidade, afirmam que a CUT é uma organização dominada pelo setor público; de outro, os dirigentes cutistas, em uma postura essencialmente defensiva, negam o predomínio destes trabalhadores no interior da entidade, apresentando dados que minimizam a real importância do setor público no sindicalismo cutista.

No que se refere à produção acadêmica, ganhou força nos últimos anos a tese de que a forte inserção do sindicalismo do setor público na CUT reforçou o viés estatizante da Central (Jácome Rodrigues, 1995; Martins Rodrigues e Cardoso, 1993; Nogueira, 1996 e 1999). No entanto, até o momento esta proposição não foi analisada de forma mais sistemática.

O objetivo deste trabalho é apresentar alguns elementos que permitam uma análise mais detalhada da expansão do sindicalismo do setor público na CUT. Ao mesmo tempo, procura-se demonstrar a fragilidade das proposições que associam a resistência cutista à reforma do Estado à mera defesa dos interesses corporativos dos servidores públicos.

Este texto é uma versão resumida dos capítulos II e IV da minha dissertação de mestrado, Companheiros servidores: poder político e interesses econômicos do sindicalismo do setor público na CUT, defendida em 7 de fevereiro de 2000 no Departamento de Ciência Política da Faculdade de Filosofia, Letras e Ciências Humanas da USP. Agradeço à banca examinadora, constituída dos professores doutores Maria Hermínia Tavares de Almeida (orientadora), Eduardo G. Noronha e Iram Jácome Rodrigues, as valiosas críticas e sugestões. Em outubro de 2000 este trabalho foi apresentado no GT Sindicalismo e Política, no XXIV Encontro Anual da Anpocs, quando me beneficiei dos comentários de Marco Aurélio Santana (coordenador) e demais colegas do grupo. Finalmente, quero agradecer aos pareceristas da $R B C S$ pelas críticas e sugestões e à Fundação de Amparo à Pesquisa do Estado de São Paulo (FAPESP), pela bolsa concedida para a realização da minha pesquisa de mestrado. 


\section{A CUT por setor econômico}

Em 1993, dez anos após a sua fundação, a CUT já estava consolidada como a maior e mais importante central sindical do país. Destaca-se a heterogeneidade das categorias profissionais e econômicas representadas pela entidade, o que faz da CUT a mais bemsucedida experiência de organização horizontal da história do sindicalismo brasileiro.

Dados apresentados por Comin (1994, p. 384), referentes a junho de 1993, demonstravam que dos 1.917 sindicatos filiados à CUT na época, $857(44,7 \%)$ representavam trabalhadores do setor de serviços, 635 (33,1\%), trabalhadores do setor rural, e 420 (21,9\%) representavam trabalhadores do setor industrial. Neste mesmo ano, os associados aos sindicatos do setor de serviços eram responsáveis por $55 \%$ do total de sindicalizados representados pela Central, o setor industrial respondia por $27 \%$, e o setor rural, pelos $18 \%$ restantes (Jácome Rodrigues, 1997).

Analisando dados mais recentes (CUT, Listagem de entidades filiadas, novembro de 1997), encontrei significativas mudanças na composição socioeconômica do sindicalismo cutista. Do total de 2.453 sindicatos filiados, 1.117 (45,53\%) estavam no setor de serviços, 874 (35,62\%), no setor rural, e
$462(18,83 \%)$ no setor industrial. Os setores rural e de serviços foram os principais responsáveis pelo crescimento do número de sindicatos filiados à CUT entre 1993 e 1997, o primeiro apresentando um crescimento de $37,64 \%$ e o segundo, de $30,34 \%$. O setor industrial, por sua vez, apresentou, no mesmo período, um crescimento de apenas 10\% no número de sindicatos filiados à Central.

Em parte, como vários autores já observaram, o sindicalismo cutista acompanha as tendências mais gerais do mercado de trabalho, no sentido do crescimento do setor de serviços e retração do setor industrial (Jácome Rodrigues, 1997; Nogueira, 1999). Contudo, há um outro fator que contribuiu para o crescimento da Central nos últimos anos: o aumento do número de sindicatos do setor rural. Neste ponto, é importante observar que, em larga medida, este crescimento está relacionado à filiação da Confederação Nacional dos Trabalhadores da Agricultura (Contag) à CUT em agosto de 1995 (Informacut, $\mathrm{n}^{-}$257, setembro de 1995). ${ }^{1}$

Assim, podemos associar o crescimento da CUT nos quatro anos que antecederam o VI Congresso da entidade a dois tipos de fatores: o primeiro, que podemos chamar de estrutural, corresponde ao próprio crescimento do setor de serviços nas sociedades capitalistas contemporâ-

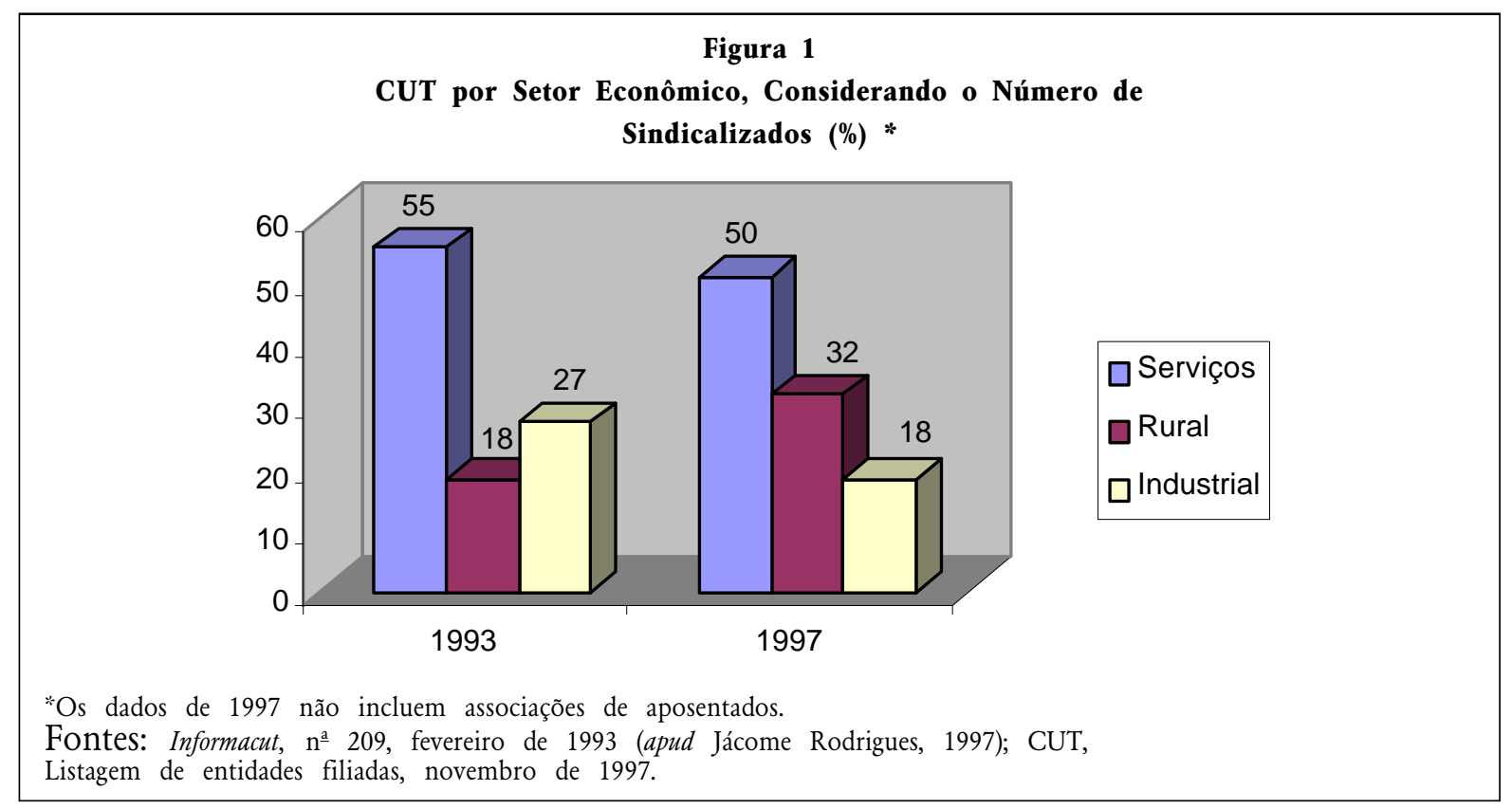


neos; o segundo, conjuntural, deve-se, essencialmente, à filiação da Contag.

No que se refere ao peso relativo dos setores econômicos, também constatei uma significativa inversão no peso proporcional das categorias no interior do sindicalismo cutista.

Como é possível observar (Figura 1), entre 1993 e 1997 não houve uma alteração substancial na participação relativa do setor de serviços no sindicalismo cutista, permanecendo esta em torno de 50\% dos associados da CUT. No entanto, ocorreu uma significativa inversão na participação dos trabalhadores rurais e industriais: os associados dos sindicatos rurais, que em 1993 representavam 18\% dos sócios da Central, em 1997 passaram a representar 32\% dos sindicalizados; inversamente, o setor industrial, que em 1993 representava 27\% dos trabalhadores associados à entidade, teve seu peso reduzido para cerca de 18\% em 1997.

\section{O setor público na CUT}

Em um conhecido trabalho sobre o III Congresso Nacional da CUT (III CONCUT), Martins Rodrigues (1990, pp.115-117) dividiu a influência da Central em três grandes setores:

a) setor estatal - telefônicos; petroleiros; trablhadores em processamento de dados; traba- lhadores nas indústrias urbanas (gás, eletricidade, água e esgoto); funcionalismo público (administração pública federal, estadual e municipal); saúde; educação (professores de primeiro, segundo e terceiro graus e servidores das universidades e dos estabelecimentos do ensino da rede pública) e previdenciários;

b) setor privado - trabalhadores rurais; químicos e petroquímicos; metalúrgicos e trabalhadores no ramo de vestuário;

c) setor de serviços - transporte (aéreo, marítimo-fluvial, metroviário, ferroviário); comerciários (hotelaria, comércio varejista e atacadista, autônomos, turismo, armazéns e empregados de estabelecimentos de saúde); bancários e empregados no setor financeiro.

A classificação proposta por Martins Rodrigues (1990) teve como objetivo aferir a influência da CUT por setor econômico; entretanto, a partir de uma classificação similar, também é possível mensurar o peso relativo do setor público na Central.

A Figura 2 representa o peso relativo dos setores econômicos na CUT, considerando o número de trabalhadores na base, o número de sócios e o número de sócios quites por setor de atividade econômica. ${ }^{2}$

De acordo com o tipo de classificação adotado neste trabalho, isto é, isolando-se o setor

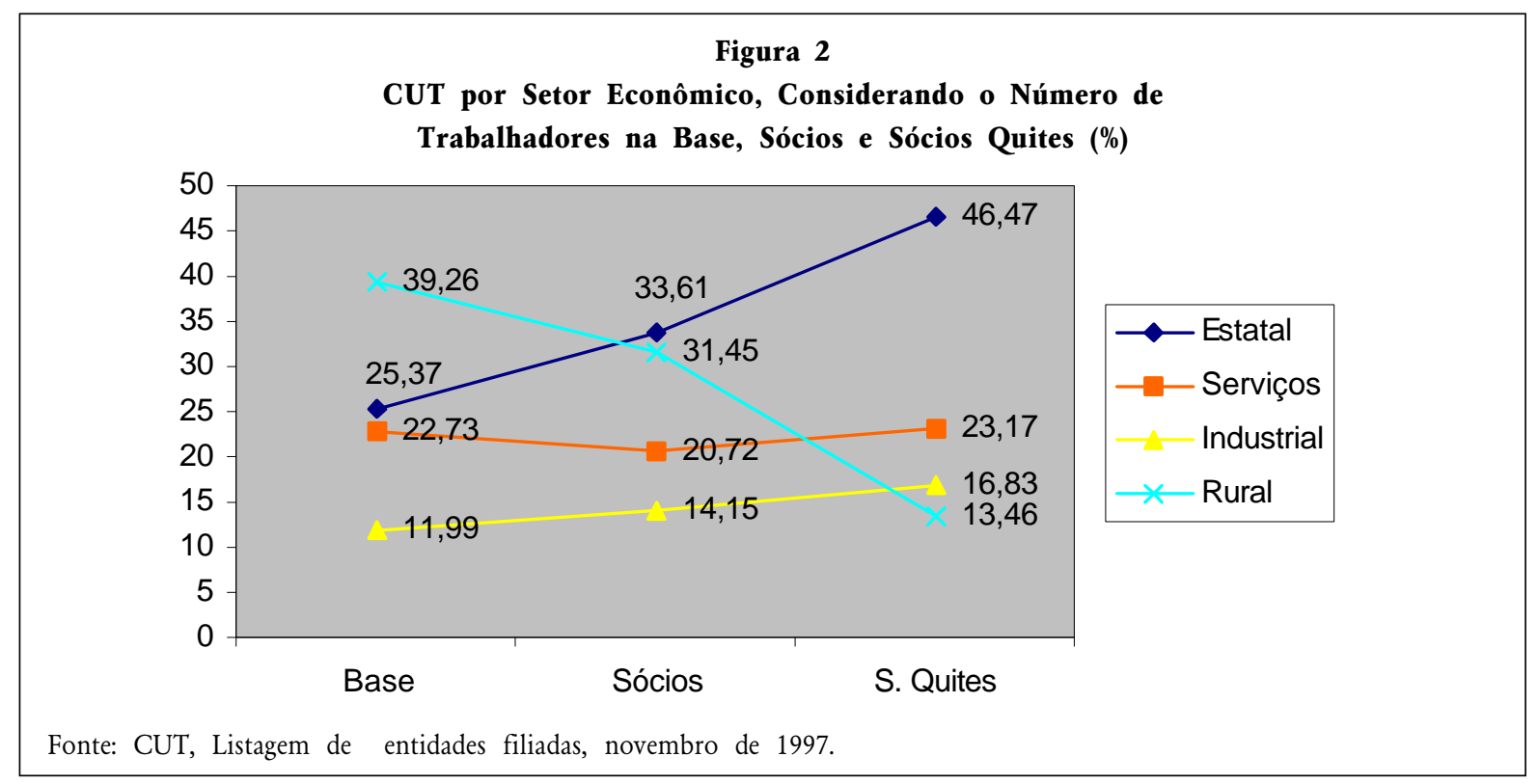


público das demais categorias econômicas, verifica-se que cerca de 39\% dos trabalhadores da base sindical cutista estão no setor rural; $25 \%$ no setor estatal; $23 \%$ no setor de serviços e $12 \%$ no setor industrial (Figura 2).

Até aqui nenhuma novidade em relação aos dados apresentados pela própria CUT, referentes à participação dos setores econômicos na base da Central, quais sejam: $37 \%$ de trabalhadores rurais, $25 \%$ de trabalhadores do setor público, 23\% de trabalhadores do setor de serviços e $15 \%$ de trabaIhadbres incustriais Informacut, $\mathrm{n}^{\mathrm{o}}$ 253, maio de 1995). O novo está no peso relativo dos setores de atividade em termos do número de sindicalizados. Neste caso, os dados revelam uma significativa inversão na posição dos trabalhadores do setor público e do setor rural em relação à base cutista. Enquanto os trabalhadores rurais diminuem seu peso entre os trabalhadores sindicalizados, passando de 39\% na base para 31\% dos sócios, os trabalhadores do setor público fortalecem sua presença entre os sindicalizados da Central, saltando de $25 \%$ na base para $34 \%$ dos sócios. Já os trabalhadores do setor de serviços e da indústria praticamente não alteram seu peso entre os sócios da CUT - respectivamente, 20,72\% e 14,15\% (Figura 2).

Contudo, os dados mais significativos referem-se à categoria de sócios quites, isto é, à proporção de trabalhadores em condições potenciais de participar das instâncias decisórias e organismos dirigentes da CUT. ${ }^{3}$ Entre os sócios quites, os trabalhadores do setor público dobram seu peso no sindicalismo cutista: se na base da CUT eles são apenas $25 \%$ dos trabalhadores, entre os sócios quites eles são cerca 47\%. Em seguida vêm os trabalhadores do setor de serviços (23\%), os trabalhadores do setor industrial (7\%) e, finalmente, os trabalhadores rurais, perfazendo $13 \%$ do total de sindicalizados quites com a Central.

Assim, se considerarmos que na base estão os trabalhadores com menor potencial de intervenção nas decisões políticas da CUT, e entre os sócios quites estão os trabalhadores com maior potencial para influir nas decisões da Central, percebemos que os trabalhadores do setor público aumentam sua presença entre aqueles que estão aptos para intervir nas instâncias decisórias e organismos dirigentes da entidade; inversamente, os trabalhadores do setor rural, que têm forte presença na base cutista, tendem a diminuir seu peso entre os trabalhadores com maior possibilidade de intervir nos rumos da Central, isto é, aqueles que efetivamente participam dos congressos, das plenárias e da composição da direção da CUT.

A participação do setor industrial e de serviços, por sua vez, não sofre uma alteração significa-

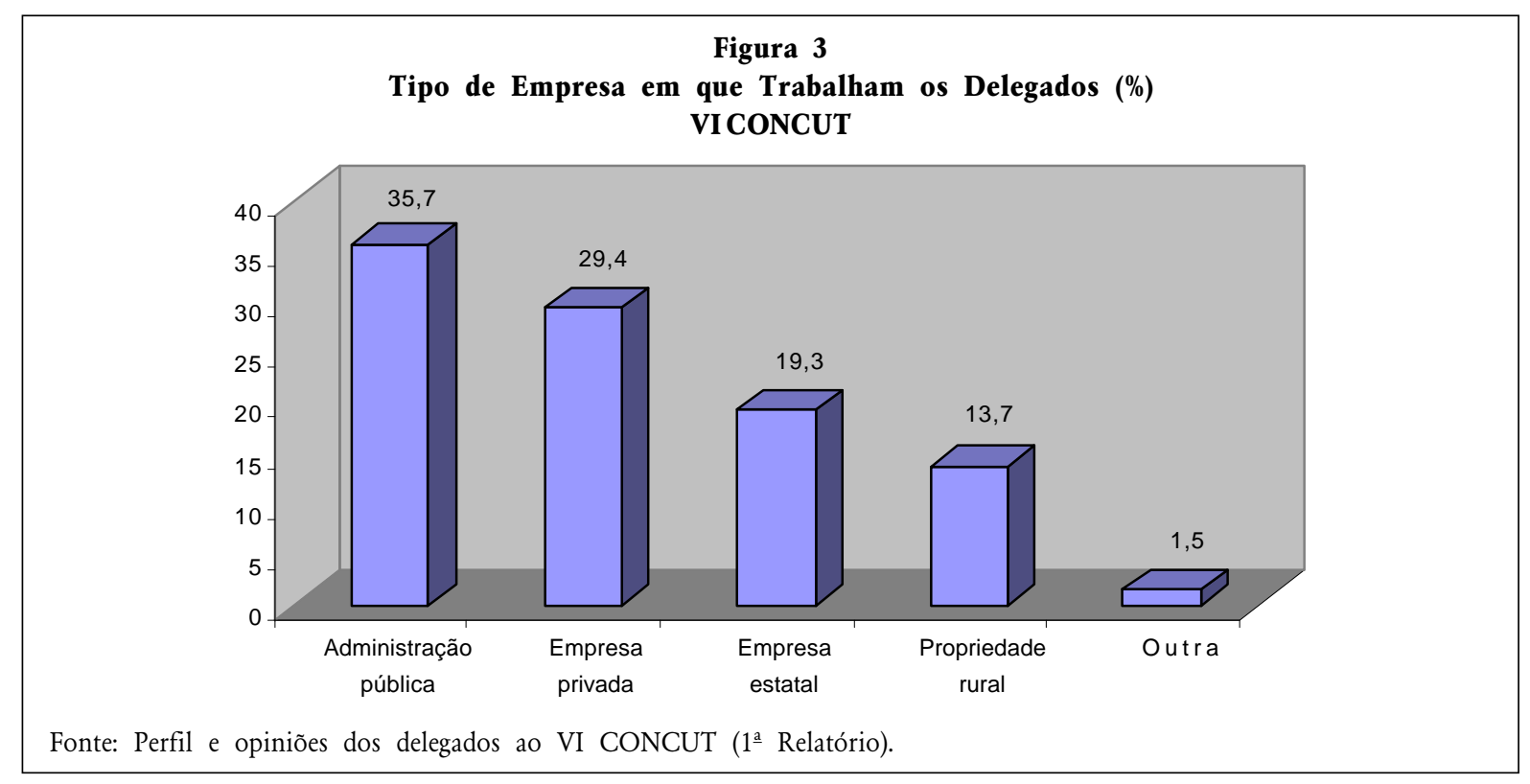


tiva quando é comparada à presença destes setores na base e entre os sócios quites da CUT. O setor de serviços, por exemplo, corresponde a $22,37 \%$ da base cutista e a $23,17 \%$ dos sócios quites, enquanto o setor industrial perfaz $12 \%$ da base e $17 \%$ dos sócios quites.

Finalmente, também é importante observar que a significativa presença de servidores públicos e empregados em estatais entre os sócios quites da CUT proporciona a estes trabalhadores uma expressiva participação nas instâncias deliberativas da Central.

A Figura 3 apresenta o tipo de empresa em que trabalhavam os delegados do VI CONCUT. Somando-se a porcentagem dos trabalhadores em empresas estatais (19,3\%) com a dos servidores públicos (35,7\%), constata-se que a maioria absoluta $(55 \%)$ dos delegados presentes no VI CONCUT pertencia ao setor público (empresas estatais, autarquias, fundações ou serviço público).

Percebe-se, então, uma tendência de aumento do peso relativo dos trabalhadores do setor público nas instâncias de maior poder decisório do sindicalismo cutista. Com efeito, retomando os dados referentes a 1997, constata-se que os trabalhadores do setor público (servidores e empregados em estatais) representavam $25 \%$ da base, $34 \%$ dos sindicalizados, $47 \%$ dos sócios quites e 55\% dos delegados presentes no VI Congresso Nacional da CUT (Figura 4).

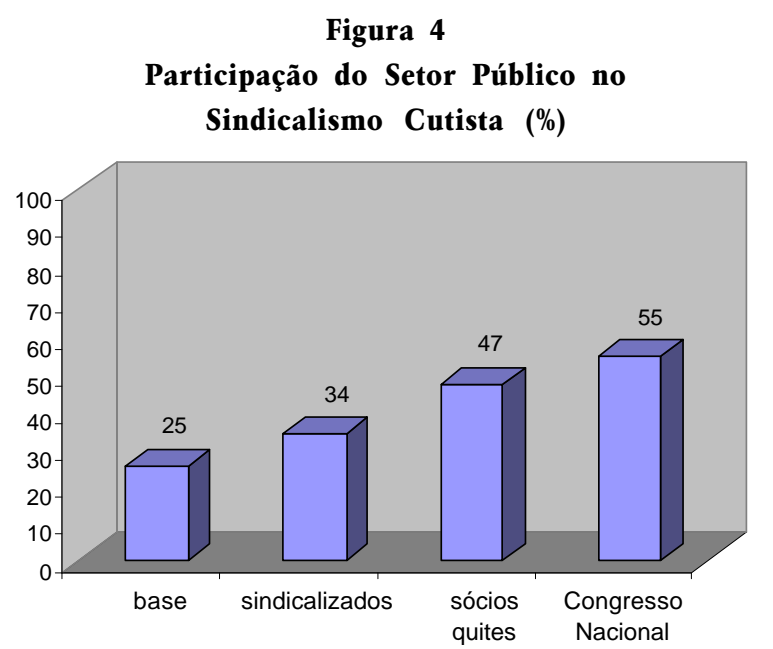

Fonte: Silva (2000).

\section{A participação do setor público na direção da CUT}

A importância do setor público no sindicalismo cutista também pode ser verificada por meio da análise da participação dos servidores públicos e empregados em estatais na direção da CUT. O Quadro 1 expressa a participação dos sindicatos que representam, predominantemente, trabalhadores do setor público na Direção Executiva Nacional da entidade desde a sua fundação.

Os sindicatos que representam, predominantemente, trabalhadores do setor público (serviço

Quadro 1

Executiva Nacional da CUT por Setor de Atividade

\begin{tabular}{lrrrrrrrrr}
\hline & \multicolumn{1}{c}{ Setor } & \multicolumn{1}{c}{ Público } & \multicolumn{2}{c}{ Setor } & Privado \\
\hline & \multicolumn{1}{c}{ Serviços } & \multicolumn{2}{c}{ Estatais } & \multicolumn{2}{c}{ Urbanos } & \multicolumn{2}{c}{ Rurais } & Total \\
\hline & $\mathrm{N}$ & $\%$ & $\mathrm{~N}$ & $\%$ & $\mathrm{~N}$ & $\%$ & $\mathrm{~N}$ & $\%$ & $\mathrm{~N}$ \\
I CONCLAT & 1 & 6,67 & 2 & 13,33 & 8 & 53,33 & 4 & 26,67 & 15 \\
I CONCUT & 2 & 13,33 & 1 & 6,67 & 8 & 53,33 & 4 & 26,67 & 15 \\
II CONCUT & 3 & 20,00 & 1 & 6,67 & 8 & 53,33 & 3 & 20,00 & 15 \\
III CONCUT & 3 & 20,00 & 2 & 13,33 & 9 & 60,00 & 1 & 6,67 & 15 \\
IV CONCUT & 7 & 28,00 & 2 & 8,00 & 14 & 56,00 & 2 & 8,00 & 25 \\
VCONCUT & 10 & 40,00 & 3 & 12,00 & 11 & 44,00 & 1 & 4,00 & 25 \\
VI CONCUT & 8 & 32,00 & 4 & 16,00 & 11 & 44,00 & 2 & 8,00 & 25 \\
\hline
\end{tabular}

Fontes: I Conclat, I, II, III CONCUT: Martins Rodrigues (1990); IV CONCUT: Resoluções (1991); V CONCUT: Resoluções (1994); VI CONCUT: Resoluções (1997). 
público e empresas estatais) mais do que dobraram sua participação na Executiva Nacional da CUT nos últimos 14 anos: de 20\% dos cargos no I CONCLAT para 48\% dos cargos no VI CONCUT. Em contrapartida, os sindicatos do setor privado (urbanos e rurais), que no congresso de fundação da CUT ocupavam $80 \%$ dos cargos da Executiva da entidade, passaram a ocupar 52\% desses cargos no VI CONCUT. Os sindicatos rurais foram os que mais perderam cargos na Executiva da Central nos últimos anos: ocupavam 26,67\% dos cargos em 1983 e passaram a ocupar apenas 8\% deles em 1997.

Ao que tudo indica, a mudança nos critérios de eleição dos delegados aos congressos da CUT, aprovada em 1988, não apenas contribuiu para diminuir a presença dos trabalhadores rurais nos congressos, como também proporcionou o aumento do peso do setor público na direção da entidade, em detrimento do setor rural. Neste caso, cumpre observar que, exceto no IV CONCUT, quando houve um aumento do número de diretores executivos, toda vez que aumentou a participação do setor público na direção da Central, a representação dos rurais diminuiu. Inversamente, no VI CONCUT, quando diminuiu a participação do setor público, aumentou a presença do setor rural na direção da CUT (Quadro 1).

A forte presença do setor público na direção da CUT fica ainda mais evidente quando é considerado o vínculo de emprego dos dirigentes que compõem a Executiva Nacional da Central (Quadro 2).

Quadro 2

Direção Executiva Nacional da CUT $1997 / 2000$

\begin{tabular}{lllll}
\hline Cargo & Nome & Profissão & Setor & UF \\
\hline Presidente & Vicentinho & Metalúrgico & PRIVADO & SP \\
Vice & João Vaccari Neto & Bancário & ESTATAL & SP \\
Sec. Geral & João Felício & Professor & PÚBLICO & SP \\
$1^{\underline{a}}$ Secretário & José Cabral & Téc. inform. & ESTATAL & PE \\
Tesoureiro & Remigio Todeschini & Téc. seg. ocup. & PRIVADO & SP \\
$1^{\underline{a}}$ Tesoureiro & Antônio C. Spis & Petroleiro & ESTATAL & SP \\
Sec. Rel. Intern. & Kjeld A. Jakobsen & Téc. Eletrotécnica & ESTATAL & SP \\
Sec. Pol. Sind. & Jorge Luiz Martins & Sapateiro & PRIVADO & SP \\
Sec. Form. & Altemir A. Tortelli & Agricultor & RURAL & RS \\
Sec. Imp. Divulgação & Sandra Cabral & Professora & PÚBLICO & GO \\
Sec. Pol. Sociais & Pascoal Carneiro & Metalúrgico & PRIVADO & BA \\
Sec. Organização & Marcelo Borges & Economista & ESTATAL & RJ \\
Diretores & executivos: $:$ & & & \\
1 & Gilda Almeida & Farmacêutico & PRIVADO & SP \\
2 & José Maria & Metalúrgico & PRIVADO & MG \\
3 & Júlio Turra & Professor & PRIVADO & SP \\
4 & Júnia Gouveia & Serv. Pública & PÚBLICO & SP \\
5 & Lujan M. B. Miranda & Professora & PÚBLICO & PI \\
6 & Luzia O. Fati & Agricultora & RURAL & PA \\
7 & Mônica Valente & Psicóloga & PÚBLICO & SP \\
8 & Paulo F. Coutinho & Bancário & ESTATAL & ES \\
9 & Pedro Ivo & Bancário & ESTATAL & CE \\
10 & Rafael F. Neto & Professor & PÚBLICO & SP \\
11 & Rita de Cássia & Metalúrgica & PRIVADO & MG \\
12 & Silvana Klein & Serv. Pública & PÚBLICO & RS \\
13 & Wagner Gomes & Metroviário & ESTATAL & SP \\
\hline
\end{tabular}

Fonte: CUT (1997b). 
Apesar de dividida pelos diversos ramos de atividade, a grande maioria dos dirigentes da Central é do setor público (servidores e empregados de estatais). Na direção nacional eleita no VI CONCUT, por exemplo, os funcionários públicos e empregados em estatais ocuparam mais de 60\% dos cargos da Executiva da entidade: 15 dos 25 existentes.

Finalmente, nota-se que os dirigentes sindicais do setor público também exercem papel de destaque nas Executivas estaduais da CUT (Quadro 3).

Entre os 27 presidentes eleitos para as CUTs estaduais (incluindo a recém-criada CUT Roraima), 17 (67\%) eram trabalhadores do setor público. Neste caso, é importante registrar que todos os bancários eleitos para as CUTs estaduais eram funcionários de bancos públicos: Orency Francisco da Silva (Caixa Econômica Federal); Jorge Pedro Caggiano Peres (Banco do Brasil); Roberto Vans Olsten (Banestado); Jorge Alfredo Streit (Banco do Brasil).

Como observei no início deste artigo, os dados sobre a participação do setor público no sindicalismo cutista envolvem uma intensa e controvertida polêmica, na qual se destacam duas posições. A primeira, difundida pelos críticos da Central, sustenta que a CUT seria refém do sindicalismo do setor público; portanto, seria inviável quaisquer negociações com a entidade em torno das reformas estruturais implementadas no país nas últimas décadas. A segunda, em resposta à primeira, minimiza o peso e a influência do sindi-

Quadro 3

Relação dos Presidentes das CUTs Estaduais por Sindicato $1997 / 2000$

\begin{tabular}{lll}
\hline UF & Nome & Sindicato \\
\hline AC & Plácido Teixeira Figueiredo Leite & Sindicato dos Trabalhadores em Educação \\
AL & José Évio Lopes Lima & Sindicato dos Servidores Públicos Federais \\
AM & Edilon Melo de Queiroz & Sindicato dos Metalúrgicos de Manaus \\
AP & Errolflynn de Souza Paixão & Sindicato dos Servidores Públicos Federais \\
BA & Luís Denis Graça Soares & Sinergia \\
CE & Antonio Eudes Xavier & Comerciários de Fortaleza \\
DF & José Lucymar Zunga Alves Lima & Sinttel \\
ES & Martin José Covre & Sindicato dos Trabalhadores da Construção Civil de Vitória \\
GO & José Antonio de Oliveira & Sinttel \\
MA & Raimundo Monteiro dos Santos & Sindicato dos Servidores Públicos Federais \\
MG & Paulo Cesar Funghi & Metalúrgicos de BH e Contagem \\
MS & Antonio Carlos Biffi & Federação dos Trab. em Educação do Mato Grosso do Sul \\
MT & Orency Francisco da Silva & Bancários do Mato Grosso \\
PA & Advoncil Candido Siqueira & STR de Ourilândia do Norte \\
PB & Hamarabi Duarte & Sinttel \\
PE & Jorge Pedro Caggiano Peres & Bancários de Pernambuco \\
PI & João de Deus Souza & Sindicato dos Trabalhadores da Educação Básica \\
PR & Roberto Vans Olsten & Bancários de Curitiba \\
RJ & Alcebíades de Souza Teixeira Filho & Sinpro/RJ \\
RN & João Batista de Lima Filho & Sindicato dos Previdenciários \\
RO & Jorge Alfredo Streit & Bancários de Rondônia \\
RS & Francisco Jorge Vicente & Metroviários de Porto Alegre \\
SC & Valdeci José da Silva & Trabalhadores do Vestuário e Calçados de Criciúma \\
SE & Francisco Gualberto da Rocha & Sindipetro \\
SP & José Lopes Feijó & Metalúrgicos do ABC \\
TO & Wilmar Mendes & STR de Colinas \\
\hline
\end{tabular}

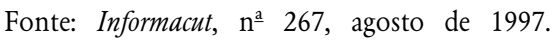


calismo do setor público na CUT; em larga medida, corresponde à própria posição da Central.

Para além desses enfoques dicotômicos, a hipótese deste trabalho é que o peso quantitativo dos trabalhadores do setor público na CUT não se transforma, automaticamente, em domínio sobre o processo de tomada de decisão no interior da Central.

De fato, para se discutir a influência do sindicalismo do setor público na CUT é necessário analisar um conjunto complexo de fatores que medeiam a ascendência dos interesses políticos e econômicos destes trabalhadores na entidade, tais como: a conjuntura política e econômica em que são lançadas as reformas, os canais institucionais criados para a participação sindical no processo reformista, o grau de interesse dos sindicatos em áreas específicas da reforma e, no caso específico da CUT, a correlação de forças entre as correntes políticas e os sindicatos filiados à Central. É o que procuro mostrar a seguir.

\section{A CUT e a reforma da Previdência}

A produção acadêmica sobre reforma do Estado chama a atenção, com freqüência, para duas características intrínsecas aos processos reformistas: (a) as reformas implicam perdas certas e imediatas para grupos específicos, mas benefícios incertos e difusos para o conjunto da sociedade (Almeida e Moya, 1997; Haggard e Kaufman, 1995; Limongi e Figueiredo, 1998; Torre, 1996 e 1997); (b) o processo reformista envolve interesses e constrangimentos institucionais peculiares a cada área do aparelho estatal a ser reformada (Melo, 1993 e 1998).
Em geral, tais proposições são utilizadas para demonstrar as dificuldades dos governantes para formar coalizões de apoio às reformas, partindo do pressuposto de que os setores atingidos pela agenda reformista tendem a se organizar com mais rapidez e eficácia do que aqueles que seriam potencialmente beneficiados. Entretanto, como pretendo demonstrar, a construção de coalizões também constitui um grande desafio para os atores políticos que se opõem às reformas.

No caso do sindicalismo cutista, por exemplo, verifica-se que a Central encontrou grandes dificuldades para mobilizar categorias econômicas e profissionais que não eram afetadas diretamente por políticas específicas da reforma do Estado, como a reforma administrativa e a quebra do monopólio estatal. Por outro lado, o maior grau de mobilização e formalização de propostas logrado pela CUT foi verificado no debate sobre a reforma da Previdência, a qual atingia de forma direta todas as categorias representadas pela entidade.

O fato de a CUT não apresentar propostas para a reforma administrativa e quebra do monopólio estatal é apresentado, normalmente, como um indicador da influência do setor público nas decisões políticas da Central, haja vista que predominou entre os sindicatos do setor público a recusa às negociações e apresentação de propostas alternativas para a reforma do Estado (Silva, 2000).

Contudo, paradoxalmente, este mesmo fato representa um obstáculo para uma análise mais sistemática da influência dos trabalhadores do setor público na posição da CUT em relação à reforma do Estado. Isto porque, nestas áreas, a postura dos dirigentes da Central, tanto do setor

Quadro 4

Posição da CUT, segundo Setor de Atividade Atingido pela Reforma Constitucional

\begin{tabular}{|c|c|c|c|}
\hline \multirow[t]{2}{*}{ Área } & \multicolumn{2}{|c|}{ Status quo } & \multirow[t]{2}{*}{ Proposta/Negociação } \\
\hline & Diretamente & Indiretamente & \\
\hline Monopólio estatal & Público & Privado & Não \\
\hline Reforma administrativa & Público & Privado & Não \\
\hline Reforma da previdência & Público/Privado & & $\operatorname{Sim}$ \\
\hline Reforma tributária & & Público/Privado & $\operatorname{Sim}$ \\
\hline
\end{tabular}

Fonte: Silva (2000). 
público quanto do setor privado, limitou-se à recusa da proposta governista e à afirmação de "princípios gerais" que deveriam ser os "pressupostos” da administração dos serviços públicos e das empresas estatais.

Em outras palavras, como se tratava de afirmar apenas "pontos consensuais", e não de apresentar propostas passíveis de negociação, no caso da reforma administrativa e da quebra do monopólio estatal, é mais difícil distinguir a posição predominante entre as lideranças sindicais do setor público daquela predominante entre as lideranças do setor privado.

Diante desta dificuldade, optei por concentrar a análise no debate em torno da reforma da Previdência, uma vez que, neste caso, tanto os trabalhadores do setor público quanto os do setor privado foram atingidos diretamente pela proposta reformista. Ademais, no caso da reforma da Previdência, a postura defensiva dos dirigentes sindicais do setor público foi contraposta à disposição de importantes lideranças sindicais do setor privado, notadamente do próprio presidente da CUT, de negociar os rumos da reforma com o governo.

Assim, embora a postura defensiva em relação às reformas tenha predominado nas áreas em que apenas os trabalhadores do setor público eram afetados diretamente, nas outras áreas - em que tanto os trabalhadores do setor público quanto os do setor privado eram atingidos de forma direta ou indireta - predominou uma posição mais propositiva (Quadro 4).

Neste sentido, o debate e as negociações em torno da reforma da Previdência assumem importância central na análise da posição da CUT em relação à reforma do Estado brasileiro, haja vista que nesta área da reforma estatal as divergências de interesses e de concepções das lideranças cutistas vieram a público com maior veemência.

\section{Centrais e governo: a concertação "desconcertada"}

No início de 1996, considerando as dificuldades para aprovar a proposta de reforma da Previdência no Congresso Nacional, o governo Fernando Henrique Cardoso decidiu convocar as centrais sindicais para negociar a reforma do sistema previdenciário.

A primeira rodada de negociações aconteceu em 11 de janeiro de 1996. A principal divergência foi a proposta de substituição da aposentadoria por tempo de serviço pela aposentadoria por tempo de contribuição. A princípio, das três centrais sindicais (CGT, CUT e Força Sindical), apenas a Força Sindical (FS) aceitou a proposta governista. Contudo, no decorrer do processo de negociação, tanto o governo quanto os sindicalistas passaram a flexibilizar suas posições. De um lado, o governo aceitou abandonar as propostas de limite de idade (60 anos), unificação dos critérios de concessão de benefícios (homens e mulheres) e fim da aposentadoria especial para os professores. De outro, o presidente da CUT, Vicentinho, comprometeu-se a defender os termos do acordo na direção nacional da Central, inclusive a aposentadoria por tempo de contribuição. No que tange às demais centrais, os pontos acertados pareciam ser suficientes para garantir o sucesso das negociações.

Assim, quatro dias após o início das negociações, os ministros Paulo Paiva (Trabalho) e Reinhold Stephanes (Previdência) e os presidentes das CGT, CUT e FS comprometeram-se a formalizar o acordo em cerimônia com a presença do presidente da República. Inicia-se então um período de intenso debate no interior do sindicalismo cutista e na esquerda brasileira como um todo. Os termos previstos pelo acordo foram duramente criticados, não apenas pelas correntes minoritárias na Central, mas também por militantes da própria Articulação Sindical, corrente política de Vicentinho. Além disso, o resultado da negociação ainda foi criticado pelos principais partidos de oposição: PT, PDT e PC do B.

As principais críticas referiam-se à substituição da aposentadoria por tempo de serviço pela aposentadoria por tempo de contribuição, ao fim da aposentadoria proporcional e da aposentadoria especial para os professores universitários e às novas regras para aposentadoria integral no serviço público.

Não havia novidade na reação dos grupos que disputam com a Articulação Sindical a direção da CUT. Em geral, esses agrupamentos sempre 
foram refratários às negociações com o governo e empresários. O novo estava na divisão da própria corrente política de Vicentinho.

Ocorre que, ainda que favorável ao acordo, a Articulação teria de prestar contas à sua base sindical no setor público. Neste ponto, cumpre observar que, dentre as categorias organizadas na CUT, o setor que mais perderia com a conclusão do acordo seria o funcionalismo. Assim, sob forte oposição de servidores públicos, professores universitários, bancários, dirigentes das correntes minoritárias e dos partidos de esquerda, a direção nacional da CUT optou por não assinar o acordo e insistir na continuidade das negociações.

Inaugura-se mais um período de ambigüidade na prática sindical cutista: de um lado Vicentinho procurava chegar a um acordo aceitável ao menos para os militantes de sua tendência política; de outro, as lideranças sindicais cutistas do setor público davam várias demonstrações da sua discordância com a política adotada pela direção da entidade.

Em uma plenária nacional realizada em 21 de janeiro de 1996, representantes de 17 sindicatos e federações de servidores públicos federais filiados à CUT aprovaram a retirada da Central das negociações com o governo. Nesta mesma plenária teria sido apresentada e derrotada uma proposta de pedido de renúncia do presidente da CUT (Folba de S. Paulo, 22/1/1996, pp. 1-8).

Dez dias depois, em 31 de janeiro de 1996, o presidente do Sindsep-DF (Sindicato dos Servidores Públicos Federais), Ismael César, responsabilizou o presidente da CUT pelo fracasso de uma paralisação de 24 horas do funcionalismo por melhores salários e contra a reforma da Previdência: "As categorias estão desanimadas e decepcionadas com a postura do Vicentinho e da CUT de aceitar negociar com o governo" (Folba de $S$. Paulo, 31/1/1996, pp.1-5).

Finalmente, no começo de fevereiro, dirigentes da Associação Nacional dos Docentes do Ensino Superior (ANDES) e do Sindicato dos Petroleiros de Duque de Caxias assinaram nota em conjunto com dirigentes sindicais das correntes Movimento por uma Tendência Socialista e Corrente Sindical Classista, em que faziam as seguintes considerações sobre a reunião da direção nacional da CUT que decidiria se a Central deveria ou não continuar no processo de negociação com o governo:

É absolutamente inaceitável que uma instância de direção, que reunirá apenas a cúpula da Central, decida sobre a questão em pauta [o acordo com o governo] [...] Uma decisão tomada em uma instância como esta [a direção nacional], que abre mão de qualquer direito dos trabalhadores, será passível de questionamento e será questionada, pois estará ferindo princípios fundamentais da nossa Central, como a democracia e a soberania da base. Folba de S. Paulo, 1/2/1996, pp. 1-6)

Neste clima de crescente polarização política, a retomada das negociações, longe de caminhar para a conclusão do acordo, tornou-se cada vez mais marcada por desencontros, desmentidos e acusações recíprocas de intransigências. $O$ fato é que não havia mais consenso, nem mesmo entre os pares, sobre os rumos que deveria tomar a reforma previdenciária: de um lado, havia um claro desentendimento entre o líder do governo, o ministro da Previdência e o relator da emenda da Previdência sobre os termos do acordo; de outro lado, na CUT, os modestos avanços alcançados nas negociações não eram suficientes para arrefecer a resistência de uma parcela expressiva dos dirigentes sindicais cutistas e, a cada nova reunião, tornava-se mais insustentável a permanência da Central no processo de negociação.

Para completar esse quadro já caótico, a FS, que sempre defendeu o "entendimento" entre governo, trabalhadores e empresários, desta vez, de forma inédita, foi a primeira a abandonar a mesa de negociações.

Finalmente, após sucessivos conflitos no interior da Comissão Especial da Reforma da Previdência, o então presidente da Câmara dos Deputados, Luiz Eduardo Magalhães (PFL-BA), “alegando um brecha regimental”, utilizou um expediente restrito às "emendas de plenário" para encaminhar o substitutivo do relator Euler Ribeiro diretamente para o plenário da Câmara (Figueiredo e Limongi, 1998). Mas a essa altura do debate o substitutivo do relator não tinha o apoio nem das centrais, nem do governo, nem dos próprios deputados. 
Em 6 de março de 1996, não obstante a "manobra governista", o relatório foi rejeitado pelo plenário por 294 votos a favor e 190 contra (eram necessários 308 votos - 3/5 da Câmara - para a aprovação do substitutivo).

\section{"O corporativismo são os outros"}

A grande imprensa, o governo e as centrais sindicais adversárias responsabilizaram a CUT e o "corporativismo do setor público" pelo fracasso das negociações da reforma da Previdência. Frustrada a tentativa de acordo, o discurso predominante afirmava que a CUT era refém dos interesses corporativos dos trabalhadores do setor público e, portanto, qualquer tentativa de negociação com a Central seria inviável.

Tudo isso explica por que um líder autêntico, como é Vicentinho, faz um acordo com o Governo, e depois se vê forçado por seus correligionários de central sindical e de partido a rever parcialmente o acordo. Não tenhamos dúvida alguma do sentido dos fatos. O que estamos vendo é uma central sindical, que teve um papel histórico na restauração da democracia e na defesa dos direitos dos trabalhadores brasileiros, ser crescentemente controlada por sindicatos do setor público que defendem interesses que não representam os interesses reais dos trabalhadores brasileiros, muito menos dos trabalhadores pobres do setor privado, que constituem a grande maioria. ${ }^{4}$

Evidentemente, os trabalhadores do setor público constituem um importante segmento do sindicalismo cutista, no que se refere tanto ao seu peso quantitativo nas instâncias decisórias e organismos dirigentes da CUT, quanto à sua influência nas propostas políticas da entidade. No entanto, a meu ver, são equivocadas as análises que reduzem as decisões políticas da Central à mera defesa dos interesses corporativos desta categoria.

Antes de mais nada, é necessário lembrar que o poder de influência do sindicalismo do setor público nas decisões da CUT referentes à reforma do Estado está estreitamente relacionado à área setorial da reforma. Assim, por exemplo, esta influência tende a ser maior nas áreas em que apenas os trabalhadores do setor público são atingidos diretamente, como no caso da quebra do monopólio estatal e reforma administrativa (Quadro 4).

Ademais, em todo o mundo, independente de representar trabalhadores do setor público ou privado, são os grandes sindicatos que possuem maior influência nas decisões políticas das centrais (Martins Rodrigues, 1999; Visser, 1994). No caso da reforma da Previdência, os dois maiores sindicatos filiados à CUT, o Sindicato do Metalúrgicos do $\mathrm{ABC}$ e a APEOESP, defenderam publicamente os avanços alcançados nas negociações com o governo. ${ }^{5}$

Finalmente, como pretendo demonstrar a seguir, o setor público não constitui um bloco homogêneo na defesa intransigente de seus interesses. Ao contrário, constitui uma categoria heterogênea no que se refere às demandas, às condições de trabalho, à organização sindical e ao poder de influência no interior da CUT.

Neste sentido, é importante chamar a atenção para um fato pouco divulgado pela imprensa e por aqueles que consideraram as lideranças sindicais do setor público os principais responsáveis pelo fracasso das negociações da reforma da Previdência: o maior sindicato do país e principal sindicato do setor público filiado à CUT - a APEOESP apoiou as negociações com o governo. Mais do que isso, o ex-presidente da APEOESP e então diretor executivo da CUT, João Felício, "acompanhou Vicentinho em todas as negociações", como informava na época o periódico sindical dos professores paulistas (Jornal da APEOESP, $\mathrm{n}^{\circ}$ 213, fevereiro de 1996).

Entre os motivos para o apoio da APEOESP aos avanços alcançados nas negociações com o governo, pelo menos um era de caráter pragmático: nos termos do acordo, os professores de $1^{\underline{a}}$ e $2^{\underline{a}}$ graus conseguiram garantir a principal reivindicação da categoria, qual seja, a manutenção da aposentadoria especial na Constituição.

Assim, se é verdade que os interesses corporativos do setor público constituíram um obstáculo para a concretização do acordo, não é menos verdade que interesses igualmente corporativos de uma das categorias mais importantes do sindicalis- 
mo cutista também foram de fundamental importância para a participação da Central nas negociações da reforma previdenciária.

Portanto, é um equívoco atribuir ao corporativismo do setor público a responsabilidade pelo fracasso das negociações em torno da reforma da Previdência. Tal proposição subestima não apenas a heterogeneidade de interesses envolvidos no processo reformista como também a própria complexidade do processo de tomada de decisão política no interior da CUT.

Neste sentido, creio que a análise da participação da APEOESP nas negociações da reforma da Previdência ajuda a compreender melhor a heterogeneidade e complexidade de interesses representados pelo sindicalismo cutista.

\section{Os professores paulistas a reforma da Previdência}

Desde a malograda Revisão Constitucional de 1993, a APEOESP vinha desenvolvendo uma intensa campanha contra as reformas constitucionais. Assim, a vitória da coligação PFL-PSDB nas eleições de $1994 \mathrm{fez}$ o sindicato dos professores paulistas alertar sua base para os riscos iminentes de uma nova proposta de reforma constitucional:

A eleição de Fernando Henrique Cardoso, o aumento da bancada do PSDB e a manutenção do tamanho das bancadas conservadores dão novo fôlego aos setores que tentam realizar a Revisão Constitucional neste ano. FHC é um dos maiores defensores da revisão. Agora, como presidente da República, terá mais influência para que o processo se efetive. Isso coloca em risco os direitos sociais do conjunto dos professores e, em especial, do magistério. (Jornal da APEOESP, $\mathrm{n}^{\circ}$ 202, out.-nov., 1994, p. 4)

A iminência das reformas constitucionais levou a direção da APEOESP a desenvolver um intenso trabalho de pressão sobre o Congresso Nacional: caravanas, promoção de debates, envio de telegramas aos parlamentares e visitas às bases eleitorais de deputados e senadores da oposição e da base governista.
Em 13 de dezembro de 1995, a luta dos professores começou a surtir seus primeiros resultados: os trabalhadores em educação, ao lado de outras categorias profissionais organizadas pela CUT e demais centrais, conseguiram adiar, pela segunda vez consecutiva, a avaliação da emenda da Previdência na Comissão Especial da Câmara dos Deputados. Além do adiamento da votação, os professores ainda lograram uma primeira vitória específica: o deputado Euler Ribeiro (PMDB-AM), relator da reforma da Previdência, manteve a garantia da aposentadoria especial para os professores de $1^{\underline{a}}$ grau em seu relatório e comprometeu-se a estender a aposentadoria especial para os professores do $2^{\mathrm{a}}$ grau.

Em 1996 os professores paulistas continuaram mobilizados na defesa dos seus direitos constitucionais. Para aquele ano a diretoria da APEOESP definiu as seguintes prioridades: melhoria salarial; manutenção da aposentadoria especial e da isonomia salarial entre os inativos e ativos; garantia de emprego para todos os professores e manutenção da estabilidade ( Jornal da APEOESP, $\mathrm{n}^{-\mathbf{a}}$ 212, janeiro de 1996, p. 2).

Como é possível verificar, das três prioridades definidas pela diretoria do sindicato, duas estavam diretamente relacionadas com as reformas constitucionais: aposentadoria especial e estabilidade do servidor público. No que diz respeito à aposentadoria especial, a "boa nova" era que o governo havia recuado na proposta de extinguir a aposentadoria especial para os professores de $1^{\underline{\underline{a}}} \mathrm{e}$ $2^{\underline{a}}$ graus:

O Governo Federal, depois da força de nossa mobilização em Brasília, recuou em sua proposta de reforma da Previdência Social e alterou o texto do projeto, mantendo a aposentadoria especial para toda a categoria. Porém, continua na pauta das reformas constitucionais a reforma administrativa que pretende acabar com a estabilidade dos servidores. A APEOESP está acompanhando todos os passos da tramitação das reformas constitucionais na Capital Federal. Várias caravanas de trabalhadores continuarão em Brasília, pressionando os parlamentares para garantirem seus direitos. (Jornal da APEOESP, $\mathrm{n}^{\circ}$ 212, janeiro de 1996, p. 3) 
Este mesmo informativo que anunciava a vitória da categoria na defesa da aposentadoria especial também trazia um quadro sinóptico dos principais avanços ocorridos nas negociações entre governo e centrais sindicais em torno da reforma da Previdência, entre eles: manutenção da aposentadoria especial para os professores de $1^{\underline{\underline{a}}} \mathrm{e}$ $2^{\underline{a}}$ graus, manutenção da aposentadoria integral para os servidores públicos, gestão pública e autônoma da Previdência (Jornal da APEOESP, n ${ }^{\circ} 212$, janeiro de 1996, p. 8).

Portanto, enquanto uma parcela expressiva dos sindicatos do setor público reagia negativamente ao acordo defendido pelo governo e pelos presidentes das três centrais sindicais, a APEOESP, no seu principal órgão de comunicação, observava que a negociação havia logrado significativos avanços em relação à proposta original do Executivo.

Durante o processo de negociação, que durou cerca de dois meses (até a votação e derrota do substitutivo do deputado Euler Ribeiro no plenário da Câmara, em 6 de março de 1996), o sindicato dos professores paulistas manteve a categoria mobilizada para garantir que não houvesse recuo do governo em relação à aposentadoria especial para os professores do $1^{\underline{a}}$ e $2^{\underline{\underline{a}}}$ graus.

Neste ponto, um dos fatos que confirma o predomínio dos interesses específicos das categorias profissionais sobre a suposta unidade do setor público refere-se à manutenção da aposentadoria especial para os professores do $3^{\underline{a}}$ grau.

Ocorre que, em dado momento do trâmite da emenda da Previdência, a extensão da aposentadoria especial para os professores universitários passou a ameaçar a aposentadoria especial dos professores de $1^{\underline{a}}$ e $2^{\underline{a}}$ graus. Isto porque, após aprovado o destaque da oposição referente à extensão da aposentadoria especial ao $3^{\underline{a}}$ grau, o governo ameaçou orientar sua bancada a votar pela supressão das aposentadorias especiais de todos os professores.

Diante desta nova ameaça à aposentadoria especial, a diretoria da APEOESP retomou, imediatamente, as caravanas a Brasília. Nos dias 8 e 15 de julho seguiram 7 ônibus, conduzindo 355 professores paulistas à capital federal para garantir o direito da categoria à aposentadoria especial.
Contudo, o resultado desta nova pressão sobre os parlamentares não foi a aposentadoria especial para todos os professores, mas sim um acordo entre o governo e a oposição que retirou todos os Destaques de Votação em Separado (DVS), mantendo o texto tal como foi aprovado na Câmara em segundo turno, isto é, sem a garantia da aposentadoria especial para os professores universitários.

O trecho abaixo, extraído do Editorial do Jornal da APEOESP de julho de 1996, apresenta uma síntese do processo de negociação entre a bancada governista e a oposição:

Embora o Governo já tivesse cedido quanto ao direito de aposentadoria especial para professores de pré-escola, primeiro e segundo graus, a aprovação de emenda proposta por alguns deputados, incluindo no mesmo artigo a extensão do direito aos professores universitários, fez com que surgissem rumores de que o Governo orientaria sua bancada para votar pela subtração da aposentadoria de todos os professores.

Combinada com outros fatores de natureza política, nossa pressão surtiu efeito. Às vésperas da votação do projeto, ocorrida no dia 17 de julho, Governo e oposição fizeram um acordo em torno da retirada de todos os Destaques de Votação em Separado (DVS), mantendo-se o texto tal qual aprovado anteriormente. Levado a plenário, o texto recebeu 318 votos a favor e 136 contra, pois os partidos de esquerda discordam de vários de seus pontos. (Jornal da APEOESP, $\mathrm{n}^{\mathrm{a}}$ 218, julho de 1996, p. 3)

Esse episódio demonstra que, no processo de reforma do Estado, o setor público não constituía um bloco homogêneo na defesa de seus interesses. Ao contrário, no interior do próprio sindicalismo do setor público travava-se um intenso debate sobre o que deveria ser defendido de forma intransigente e o que poderia ser negociado pela CUT.

O resultado da negociação entre a bancada governista e a oposição, apesar de ser considerado uma vitória da categoria pelo Jornal da APEOESP, ocorreu em detrimento dos professores do $3^{\underline{a}}$ grau, 
organizados na ANDES, sindicato também filiado à CUT, mas sem o mesmo poder de influência que a APEOESP e demais sindicatos de professores de $1^{\underline{a}}$ e $2^{\underline{a}}$ graus no interior do sindicalismo cutista.

Portanto, ainda que a proposta de reforma do Estado defendida pelo Executivo motivasse uma coalizão dos servidores em defesa de seus benefícios e vantagens, na prática, no momento de negociar e apresentar propostas, não havia consenso entre as lideranças sindicais.

Mais do que isso, não se tratava apenas de diferenças entre os sindicalistas do setor público e privado, mas também de divergências no interior do próprio sindicalismo do setor público. Como vimos, mesmo no interior de um único ramo de atividade (Educação) a unidade era frágil.

Evidentemente, não se trata de emitir qualquer juízo de valor sobre as razões que levaram os dirigentes da CUT a abrir mão da defesa da aposentaria especial para os professores do $3^{\underline{a}}$ grau. Com este exemplo, meu objetivo é apenas demonstrar que, ao contrário do que normalmente se afirma, não havia uma oposição intransigente da Central em relação a todos os temas que envolvessem trabalhadores do setor público e, em alguns casos, a direção da CUT estava disposta a negociar, ainda que sob intenso protesto das categorias atingidas.

Além disso, também é importante frisar que, no sindicalismo cutista, os principais sindicatos do setor público representam servidores que exercem suas atividades em áreas consideradas "finalísticas”, notadamente saúde e educação. Por outro lado, os sindicatos representantes dos trabalhadores que exercem atividades nas áreas consideradas de "suporte", ainda que numerosos, parecem não contar com o mesmo poder de influência na direção da Central. ${ }^{6}$

De fato, como já foi observado, entre os servidores públicos que compõem a direção nacional da CUT eleita em 1997, a grande maioria exerce suas atividades nas áreas "fins", principalmente saúde e educação (Quadro 2). Ademais, dos 17 maiores sindicatos do setor público filiados à CUT, 14 (82\%) representam trabalhadores em Educação; os outros três representam previdenciários, trabalhadores em saúde e servidores públicos municipais (Quadro 5).
Com estas observações, desejo mais uma vez chamar a atenção para a heterogeneidade e complexidade de interesses que permeiam o sindicalismo cutista, o que justifica a proposição de que a influência do sindicalismo do setor público na CUT não se manifesta como domínio dos servidores públicos e empregados em estatais sobre o processo de tomada de decisão política no interior da Central.

Ao contrário, esta influência é mediada por um conjunto complexo de fatores, tais como: poder de mobilização sindical; representatividade do sindicato (em número de sócios e sócios quites); tendência política que dirige a entidade sindical; peso do sindicato nas instâncias deliberativas e organismos dirigentes da CUT etc. E, sob todas estas condições, a APEOESP era (e ainda é) o sindicato do setor público que reunia as melhores condições para influir nas decisões políticas da CUT em relação à reforma da Previdência. Era a categoria mais mobilizada no debate sobre as reformas, com maior número de sócios filiados, dirigida pela corrente majoritária na Central, com forte presença nas instâncias deliberativas (congressos, plenárias, encontros etc.) e nos organismos dirigentes da entidade (direção nacional, estadual, subsedes regionais etc.).

Portanto, afirmar que o sindicalismo do setor público foi o responsável pelo fracasso das negociações entre governo e centrais sindicais significa não apenas menosprezar a heterogeneidade e complexidade de interesses que permeiam a organização sindical no setor público, como também ignorar o papel fundamental desempenhado pelas lideranças sindicais de uma das categorias mais importantes do funcionalismo que, tendo à frente o sindicato dos professores paulistas, posicionouse favoravelmente às negociações com o governo.

\section{Considerações finais}

$\mathrm{Na}$ primeira parte deste artigo apresentei um conjunto de dados que confirma a importância do sindicalismo do setor público na CUT. Em seguida, contrariando o discurso predominante sobre $\mathrm{O}$ assunto, argumentei que o peso quantitativo dos servidores públicos e empregados em empresas 
Quadro 5

Os 25 Maiores Sindicatos Filiados à CUT - 1997

\begin{tabular}{lcc}
\hline \multicolumn{1}{c}{ Sindicato ou Associação } & UF & Sócios \\
\hline 1 Assoc. dos Professores do Ensino Oficial de São Paulo & SP & 150.386 \\
2 Sind. Trab. Ind. Metalúrgicas do ABC & SP & 96.780 \\
3 Centro dos Professores do Estado - Sind. Trab. Educação & RS & 82.792 \\
4 Sind. Dos Bancários de São Paulo & SP & 69.943 \\
5 Sind. Único Trab. Em Educação & MG & 50.000 \\
6 Sind. Trab. Em Educação - APLB & BA & 49.408 \\
7 Sind. Dos Previdenciários & RJ & 40.512 \\
8 Sind. Dos Professores das Redes Pub. Estadual e Municipal & PR & 38.792 \\
9 Sind. Dos Bancários & RJ & 37.000 \\
10 Sind. Est. Dos Profissionais da Educação & RJ & 34.200 \\
11 Sind. Trab. Ind. Metalúrgicas & RJ & 28.000 \\
12 Sind. Dos Professores & DF & 27.044 \\
13 Sind. Trab. Ind. Metalúrgicas & SP & 27.032 \\
14 Sind. Trab. Ind. Urbanas & RJ & 26.835 \\
15 Sind. Trab. Em Educação & PE & 26.385 \\
16 Afuse - Sind. Func. Serv. Da Educação & SP & 25.904 \\
17 Sind. Dos Professores & MG & 25.583 \\
18 Sind. Empreg. No Comércio & BA & 25.476 \\
19 Sind. Serv. Pub. Em Saúde & SP & 25.000 \\
20 Sind. Trab. Em Educação & AL & 23.148 \\
21 Sind. Trab. No Ensino Público & MT & 20.735 \\
22 Sind. Dos Profissionais em Educ. No Ensino Municipal & SP & 20.600 \\
24 Sind. Trab. Em Educação & CE & 20.100 \\
25 Sind. Trab. Em Transp. Rodoviários & SP & 20.000 \\
\hline TOTAL & ES & 20.000 \\
\hline
\end{tabular}

Fonte: CUT, Listagem de entidades filiadas, novembro de 1997.

estatais no sindicalismo cutista não se transforma, automaticamente, em domínio sobre o processo de tomada de decisão política na Central.

No caso da posição da CUT em relação à reforma do Estado, por exemplo, as lideranças sindicais do setor público encontraram grandes dificuldades para unificar suas demandas e estratégias, o que reduziu o poder de influência deste setor em momentos decisivos da participação da Central no debate sobre as reformas constitucionais, como foi o caso das negociações em torno da reforma da Previdência.
Neste caso, o que se verificou foi uma posição ambígua do sindicalismo do setor público cutista: se, de um lado, diversos dirigentes sindicais do setor público condenaram a participação da Central nas negociações da reforma da Previdência, de outro, importantes sindicatos do setor público, como a APEOESP, defenderam as negociações com o governo.

Assim, considerando que o sindicalismo do setor público não constituiu um bloco homogêneo na defesa de suas demandas políticas e econômicas, creio que seja um equívoco afirmar que os 
interesses corporativos dos trabalhadores do setor público inviabilizaram uma solução "concertada" para a reforma da Previdência.

Igualmente sem sentido parece ser a crítica de que as centrais sindicais, em especial a CUT, teriam defendido apenas os interesses das categorias organizadas no debate sobre a reforma do Estado. Isto porque, independente do juízo de valor que se possa emitir sobre esta questão, tal perspectiva parece criticar as lideranças sindicais por fazerem justamente aquilo que devem fazer: defender, em primeiro lugar, os interesses de seus representados.

Neste caso, retomando uma questão persistente no debate sobre as reformas estruturais, deve-se perguntar: qual seria o futuro de um dirigente sindical que estivesse sempre disposto a aceitar perdas certas e imediatas em troca de benefícios incertos e difusos? Ou, para usar uma expressão em voga neste início de século: qual seria o "destino do sindicalismo"?

\section{NOTAS}

1 A filiação de uma confederação a uma central sindical não implica a filiação dos sindicatos associados, mas pode motivar esta filiação. Este parece ter sido o caso da filiação da Contag à CUT.

2 De acordo com a classificação adotada, chegou-se aos seguintes números sobre o sindicalismo cutista: setor estatal - 4.688.430 na base, 1.982 .076 sindicalizados e 1.803.329 sócios quites; indústria - 2.214.915 na base, 834.379 sindicalizados e 653.137 sócios quites; serviços - 4.200.767 na base, 1.221.977 sindicalizados e 899.080 sócios quites; rural - 7.255.096 na base; 1.855 .198 sindicalizados e 522.174 sócios quites.

3 É a proporção de sócios quites que determina a participação das delegações nas principais instâncias deliberativas da CUT, entre elas o Congresso Nacional, que elege a direção da entidade.

4 Trecho de um artigo publicado pelo então ministro da Administração e Reforma do Estado, Bresser Pereira, nos jornais $O$ Estado de S. Paulo e $O$ Globo, em 6 de fevereiro de 1996.

5 A APEOESP é o maior sindicato do país. Em novembro de 1997 contava com 230 mil trabalhadores na base e 150.386 sindicalizados.

6 A distinção entre as "áreas finalísticas” ou "áreas-fins” e as "áreas de suporte" ou "áreas-meios" baseia-se nos trabalhos de Guedes (1994) e Marconi (1997).

\section{BIBLIOGRAFIA}

ALMEIDA, M.H.T. de e MOYA, M. (1997), “A reforma negociada: o Congresso e a política de privatização". Revista Brasileira de Ciências Sociais, 12, 34: 119-31.

CENTRAL ÚNICA DOS TRABALHADORES. (1995a), Propostas da Central Única dos Trabalhadores: dignidade e cidadania para quem faz o país. Brasília, CUT.

. (1995b), Uma nova Previdência Social no Brasil. São Paulo, CUT.

(1997a), Perfil e opiniões dos delegados ao VI CONCUT (1 $1^{\underline{a}}$ Relatório). São Paulo, CUT/ Unitrabalho.

(1997b), VI CONCUT: resoluções e registros. São Paulo, CUT.

COMIN, A.A. (1994), “A experiência de organização das centrais sindicais no Brasil", in B. Oliveira et al. (orgs.), $O$ mundo do trabalbo: crise $e$ mudança no final do século, São Paulo, Scritta.

GUEDES, C. (1994), "Os trabalhadores no setor público brasileiro: prática sindical, conquistas e armadilhas - análise do período pós-1978”, in B. Oliveira et al. (orgs.), O mundo do trabalho: crise e mudança no final do século, São Paulo, Scritta.

HAGGARD, S. e KAUFMAN, R. (1995), The political economy of democratic transitions. Princeton, Princeton University Press.

JÁCOME RODRIGUES, I. (1995), "O sindicalismo brasileiro da confrontação à cooperação conflitiva”. São Paulo em Perspectiva, 9, 3: 116-26.

(1997), Sindicalismo e política: a trajetória da CUT. São Paulo, Scritta.

LIMONGI, F. e FIGUEIREDO, A.C. (1998), "Reforma da Previdência e instituições políticas". Novos Estudos, 51: 63-90.

MARCONI, N. (1997), “Uma breve comparação entre os mercados de trabalho do setor público e privado”. Revista do Serviço Público, 48(1): 127-55.

MARTINS RODRIGUES, L. (1990), CUT: os militantes e a ideologia. Rio de Janeiro, Paz e Terra.

(1999), Destino do sindicalismo. São Paulo, Edusp. 
MARTINS RODRIGUES, L., CASTRO, M.S.P., SOCHACZESKI, S.e JÁCOME RODRIGUES, I. (1991), Retrato da CUT: delegados do III CONCUT, representação nas categorias. São Paulo, Editora da Central Única dos Trabalhadores.

MARTINS RODRIGUES, L. e CARDOSO, A.M. (1993), Força Sindical: uma análise sociopolítica. São Paulo, Paz e Terra.

MELO, M.A.B.C. de. (1993), "Anatomia do fracasso: intermediação de interesses e a reforma das políticas sociais na Nova República”. Dados Revista de Ciências Sociais, 36, 1: 119-63. (1998), A política da reforma do Estado no Brasil. Mimeo

NOGUEIRA, A.J.F.M. (1996), Trabalbo e sindicalismo no Estado brasileiro: experiências e desafios. Tese de doutorado. Campinas, Instituto de Filosofia e Ciências Humanas da Universidade Estadual de Campinas.

(1999), "Emergência e crise do Novo Sindicalismo no setor público brasileiro", in I.J. Rodrigues (org.), $O$ novo sindicalismo: vinte anos depois, Petrópolis, Vozes.

SILVA, S.J. da. (2000), Companheiros servidores: poder político e interesses econômicos do sindicalismo do setor público na CUT. Dissertação de mestrado. São Paulo, Departamento de Ciência Política da Faculdade de Filosofia, Letras e Ciências Humanas da USP.

TORRE, J.C. (1996), "O encaminhamento político das reformas”. Lua Nova, 37: 57-96.

- (1997), La política de las reformas económicas en América Latina. Santiago, Cepal.

VISSER, J. (1994). "The strength of union movements in advanced capitalist democracies: social and organizational variations", in M. Regini (ed.), Future of labour movements, Londres, Sage Publications Ltd. 